contact, or by contaminated objects. According to Jellard (1957), the main reservoirs of this organism are (a) open lesions in the mothers, babies, or staff ; $(b)$ adult skin and nasal carriers; and $(c)$ the babies themselves, the umbilical cord being one of the principal sites. More than $80 \%$ of hospital-born infants are said to develop umbilical colonization by staphylococci at the fourth day (Fairchild, Graber, Vogel, and Ingersoll, 1958). In this respect the presence of the organism in the babies' stools has not been emphasized. Since staphylococci were cultured from the stools in nearly $50 \%$ of babies by the eighth day, the stools must be regarded as a potential reservoir of infection to which appropriate action must be directed during nursery outbreaks of staphylococcal sepsis.

\section{Summary}

Rectal colonization by Staph. aureus occurred in $48 \%$ of 92 normal newborn infants by the eighth day, and was not asso- ciated with any gastro-intestinal disturbance. The finding of Staph. aureus in stool cultures from infants with diarrhoea should be regarded as incidental, unless shown to be caused by an epidemic strain. However, the prevalence of this organism in the stools may be a significant reservoir of staphylococcal spread in nursery infections.

\section{REFERENCES}

Buttiaux, R., and Pierret, J. (1949). Ann. Inst. Pasteur, 76, 480.

Crowley, N., Downie, A. W., Fulton, F., and Wilson, G. S. (1941). Lancet, $2,590$. Duff, G. L., Murray, E. G. D., and Prissick, F. H. (1953). Amer. F. med.

Duncan, J. T., and Walker, J. (1942). f. Hyg. (Lond.), 42, 474.

Fairchild, J. P., Graber, C. D., Vogel, E. H., and Ingersoll, R. L. (1958). F. Pediat., 53, 538 .

Foster, W. D., and Harris, R. E. (1960). F. Obstet. Gynaec. Brit. Cwlth, 67, 463.

Jellard,' J. (1957). Brit. med. f., 1, 925.

Martyn, G. (1949). Ibid., 1, 710.

Todd, E. W. (1922). ₹. Hyg. (Lond.), 21, 37

Williams, R. E. O., and Rippon, J. E.'(1952). Ibid., 50, 320.

\title{
Infection with Animal Helminths as a Factor in Causing Poliomyelitis and Epilepsy
}

\author{
A. W. WOODRUFF, * M.D., PH.D., F.R.C.P., F.R.C.P.ED., D.T.M.\&H. \\ B. BISSERU,† M.SC., PH.D., M.B., M.R.C.P.ED., D.T.M.\&H., D.OBST.R.C.O.G. \\ J. C. BOWE $\ddagger$ M.D., F.R.C.P.ED., D.P.H.
}

Brit. med. F., 1966, 1, 1576-1579

Earlier work demonstrated that in Britain, as in some countries overseas, the possibility of acquiring infection with Toxocara canis or $T$. cati is considerable and that this infection may account for some cases of eosinophilia and allergic states of otherwise undetermined origin (Woodruff and Thacker, 1964). In that earlier paper the possibility was discussed that larvae, in migrating, may be capable of carrying virus from the intestine to the brain and other tissues, and reference was made to the post-mortem finding by Beautyman and Woolf (1951) of a larva, almost certainly $T$. canis, in the brain of a child who had died from poliomyelitis. It was also deduced that the seeming predilection for toxocariasis to affect the eye is more apparent than real and does not indicate the full frequency with which this infection is contracted by man. The probability is that, as the eye is a relatively small organ, other larger structures are invaded more often than it is, but that invasion of the eye, by giving rise to visual disturbance, leads more commonly to medical advice being sought and the diagnosis being made than does invasion of such organs as the liver or even the brain. From involvement of the latter much less easily diagnosed symptoms are likely to arise.

Sprent (1955) demonstrated that in mice experimentally infected with $T$. canis larvae commonly migrate to the brain, and he suggested that they may occasionally be responsible for carrying viruses and other micro-organisms to it; and Mochizuki et al. (1954) demonstrated experimentally in mice that $T$. canis larvae in migrating to the brain could carry with them the virus of Japanese B encephalitis. Much important early work on the development of the infection in man was done by Beaver and his associates and is reviewed by Beaver (1962).

\footnotetext{
* Welleome Professor of Clinical Medicine, London School of Hygiene and Tropical Medicine.

† Research Assistant and Honorary Senior Medical Registrar, Hospital for Tropical Diseases, London.

$\ddagger$ Medical Director, Lingfield Hospital School, Lingfield, Surrey.
}

Having devised an antigen for determining the incidence of past toxocaral infection, and having shown that it is suitable for use in man and gives rise neither to significant numbers of falsepositive reactions in those who have not been infected nor to cross-positive reactions in persons infected with other helminths, we decided to try to answer the question whether those who gave a past history of poliomyelitis had been infected with toxocariasis more frequently or less frequently than the apparently healthy population. Conversations were held with several people on diseases the cause of which is at present unknown but which could be produced by the lesions in the brain due to small toxocaral granulomata, and Professor G. Bull suggested that some cases of epilepsy might result from them. It was therefore also decided to attempt to determine whether those with epilepsy had been more often infected with toxocariasis than healthy persons. Brain and Allan (1964) reported encephalitis with convulsions in a patient with toxocariasis, and these convulsions were later followed by many epileptic seizures.

$T$. canis and $T$. cat $i$ are ascarids of which the adults normally inhabit the intestines of dogs and cats respectively. The ova of these worms are passed in the animal's faeces and are infective to man; they develop into larvae which burrow into the human intestinal wall, whence they are taken in blood to a wide variety of organs even though the organ in which they have been most frequently demonstrated is the eye. The larvae, it seems, seldom develop into mature toxocarae in man, only one such instance having been reported prior to the publication in this issue (p. 1583) of the case of Bisseru et al. (1966). The larvae, it appears, usually wander in the tissues till they die and then stimulate granulomatous tissue formation around their disintegrating bodies.

Earlier work (Woodruff and Thacker, 1964) showed that of 300 dogs from the Home Counties $20.7 \%$ were infected with $T$. canis and of 176 cats $22.7 \%$ were infected with $T$. cat $i$, thus 
indicating that a large reservoir exists among these animals from which man could be infected. Further evidence of the size of this reservoir was sought in view of the evidence, later obtained, that human infection with toxocariasis is indeed not uncommon and that there is therefore need to establish beyond all reasonable doubt that the reservoir of infection is as large as it at first appeared.

\section{Method and Procedure}

The antigen was prepared from adult $T$. canis by the method of Fairley (1931) ; and, following the demonstration (Woodruff and Thacker, 1964) that best results are obtained with a dilution of $1 / 1,000$ of this antigen, this dilution was used throughout the present study. A positive skin reaction was taken to be one in which the initial weal doubled its area within 20 minutes and became surrounded by erythema.

At the Royal National Orthopaedic Hospital and associated institutions, and through the Shaftesbury Society, it has been possible to carry out toxocaral skin tests on 191 patients who had suffered from poliomyelitis.

At Lingfield Hospital School there are approximately 300 patients with epilepsy, and permission to carry out the toxocaral skin test on 297 was obtained ; in the Neurological Department of University College Hospital a further 52 were tested. It should be emphasized that patients at Linfield form a highly selected group of those severely affected; the vast majority of children with epilepsy attend ordinary schools. The results obtained in these groups have been compared with those obtained in apparently healthy people. The skin test was also carried out on 329 volunteers who were apparently healthy and who had had no history of having had a helminthic infection.

The method used for examining the dog's faeces for ova was that of Ridley and Hawgood (1956). The samples of animal faeces were obtained through the kind cooperation of the staff of a number of homes for dogs and cats near London.

\section{Toxocariasis and Poliomyelitis}

In the attempt to answer the question whether patients who had suffered from poliomyelitis had been infected with toxocariasis with a frequency similar to, or different from, that occurring in the normal population, the toxocaral skin test was carried out on 191 persons who had had the disease in the past. Of these, $26(13.6 \%$ ) reacted positively, as compared with $2.1 \%$ of apparently healthy persons who had positive skin reactions (Table I). Clearly this difference is highly significant $\left(\chi^{2}=26.7, \mathrm{P}<0.001\right)$.

From this investigation it appears that toxocaral infection had occurred very much more commonly among those who had had poliomyelitis than among apparently healthy persons. The most probable explanation of this difference seems to be that the toxocara larvae, in migrating from the alimentary tract to blood-vessels, had carried with them poliomyelitis virus and thus facilitated entry into the tissues of virus, or amounts of virus, larger than would otherwise have entered. Such a situation might lead to persons contracting clinically apparent poliomyelitis when they would otherwise have escaped doing so.

\section{Toxocariasis and Epilepsy}

The incidence of positive toxocaral skin tests was approximately three times as great in those with epilepsy as in healthy controls. Of 349 patients with epilepsy 26 reacted positively, as compared with seven who did so from among 329 normal controls (Table I), a difference which is significant at less than the $1 \%$ level $\left(\chi^{2}=10.6397, \mathrm{P}<0.002\right)$.
This difference is highly significant and has not occurred by chance. From this it may be deduced either that toxocaral infection can cause epilepsy or that those epileptic subjects are more prone to develop toxocaral infection than healthy persons. Certainly when a toxocara larva dies it produces a focal area of granulomatous reaction, which might well be expected to produce focal epilepsy. If many died in the cortex, as in some heavy infections, a number of foci and generalized epilepsy could develop.

TABLE I.-Results of Skin-testing with T. canis Antigen in Apparently Healthy Persons, Patients who had had Poliomyelitis, and Patients with Epilepsy

\begin{tabular}{|c|c|c|}
\hline & $\begin{array}{l}\text { No. } \\
\text { Tested }\end{array}$ & $\begin{array}{c}\text { No. giving } \\
\text { Positive Reaction }\end{array}$ \\
\hline $\begin{array}{l}\text { Apparently healthy persons without demon- } \\
\text { strable helminthic infections } \\
\text { Patients who had had poliomyelitis }\end{array}$ & $\begin{array}{l}329 \\
191 \\
349\end{array}$ & $\begin{array}{c}7(2 \cdot 1 \%) \\
26(13.6 \%) \\
26(7.5 \%)\end{array}$ \\
\hline
\end{tabular}

Further indications of the role of toxocariasis as a possible cause of epilepsy were sought by comparing various features of the illness in patients whose skin test was positive with those with epilepsy in whom the test was negative. These features are discussed below.

The possibility must be entertained that in some patients the epilepsy is not a direct result of toxocariasis but that epilepsy, mental defect, and toxocariasis result from brain injury. It may be that some epileptic patients consume soil more often than healthy persons or have come more closely into contact with dogs and cats. This could of course lead to infection, for $T$. canis and $T$. cati eggs are conveyed to soil from the faeces of infected animals.

\section{Age of Onset of Epilepsy}

It is probable that a period of several months elapses between ingestion of a toxocaral egg and development of epilepsy. if a causal relationship between the two exists. In the case reported by Brain and Allan (1964) convulsions developed six months after the start of the illness, which probably began near the time of infection. The larva or larvae on hatching from the eggs would have to migrate to the brain and produce encephalitis or one or more granulomatous foci before epilepsy is likely to develop. It is therefore improbable that epilepsy, if of toxocaral origin, would develop before the age of 6 months; indeed, it is more probable that the age of onset of the epilepsy, if due to toxocariasis, would usually be much later than this, and later than in those whose epilepsy is due to inherited defect or birth injury. The age of onset of the epilepsy in those 26 patients with a positive toxocaral skin test and in the 323 epileptics in whom the test was negative is therefore of some interest. The mean age of onset in those with a positive test was 6.5 years and in those with a negative test 7.6 years. The point of pariticular note concerning these figures is that in those showing evidence of toxocariasis the epilepsy had first deyeloped at an age consistent with a toxocaral aetiology.

\section{Family History of Epilepsy}

If epilepsy is caused by toxocariasis it is unlikely that a family history of it will be present; this history was therefore sought in each patient on whom the test was carried out. Among the 26 with a positive skin test there was a family history of epilepsy in only one case $(3.8 \%)$, while in the 323 in whom the test was negative there was such a history in 22 cases $6.8 \%$ ). This difference could have occurred by chance, but is nevertheless of considerable interest. 


\section{Contact with Dogs and Cats}

Among those who had a positive skin test and epilepsy 20 (77\%) had had a dog or cat in their household for at least three months, whereas of those whose test was negative $174(53.8 \%)$ had similarly had such contact with dogs or cats. This difference is statistically significant $\left(\chi^{2}=5.180, \mathrm{P}<0.05\right)$ (see Table II).

TABLE II.-Frequency of a Family History of Epilepsy and of Close Contact with Dogs Among Epileptics with Positive or Negative Toxocaral Skin Tests

\begin{tabular}{c|c|c|c}
\hline & $\begin{array}{c}\text { No. in } \\
\text { Series }\end{array}$ & $\begin{array}{c}\text { Family History } \\
\text { of Epilepsy }\end{array}$ & $\begin{array}{c}\text { Contaet with } \\
\text { Dogs or Cats }\end{array}$ \\
\hline $\begin{array}{l}\text { Patients with positive skin test } \\
\text { and epilepsy ... }\end{array}$ & 26 & $3.8 \%(1)$ & $77 \%(20)$ \\
$\begin{aligned} \text { Patients with negative skin test } \\
\text { and epilepsy .. }\end{aligned}$ & 323 & $6.8 \%(22)$ & $53.8 \%(174)$ \\
\hline
\end{tabular}

\section{Electroencephalograms in Patients with Epilepsy and a Positive Skin Test}

Among 24 patients at Lingfield whose skin tests were positive the electroencephalogram (E.E.G.) showed a focal origin for the fits in nine, of whom three had a history of birth injury ; so that in six of those nine a single toxocaral granuloma or a small localized group of such granulomata would be not inconsistent with the E.E.G. pattern. Among the remaining 15 with generalized, widespread, or centroencephalic types of disturbance a toxocaral origin could not be excluded, for if many larvae had invaded the brain they would be expected to cause scattered granulomata and hence generalized or widespread encephalographic disturbances.

Knowing, as we do, little of the detailed pathology and distribution of toxocaral lesions in the body in man, it has been usual to think in terms of one larva, or only a few larvae, causing damage. This concept has been encouraged by the way in which the eye has often been the only organ in which toxocaral disease has been demonstrated, but, as has been indicated by Woodruff and Thacker (1964), this predilection for the eye is almost certainly more apparent than real, and results from the readiness with which infection in the eye causes symptoms and/ or loss of vision and the relative ease with which a precise histological diagnosis can be made following the enucleation of the eye to which in the past symptoms have commonly led. Larvae in organs other than the eye therefore cause less definite and less easily diagnosed symptoms but probably occur much more often than do larvae in the eye, and infections with multiple larvae may well be common. Such a concept is supported by these E.E.G. tracings showing generalized disturbances in patients whose epilepsy could possibly be a result of multiple toxocaral granulomata or in whom multiple toxocaral lesions had been acquired since the onset of their epilepsy.

\section{Infection Rate with $\mathbf{T}$. canis and $\mathbf{T}$. cati among Dogs and Cats in the London Area}

To the 300 dogs examined in the earlier study (Woodruff and Thacker, 1964) 170 others were added. The number of those on the new series found to harbour $T$. canis ova in their faeces was $39(22.9 \%)$, making an overall total of $101(21.3 \%)$ among 470 animals infected. To the 176 cats examined in the earlier series a further 272 were added, and $54(19.9 \%)$ of these had ova of $T$. cati in their faeces, making a total of $94(21 \%)$ infected from among 448 cats. Thus on these much-increased total numbers of animals the percentage of those infected was found to be similar to that in the earlier, smaller series. Among a total of 918 domestic dogs and cats approximately one in five have been found to harbour these worms.

These incidences of toxocaral infection in animals in Britain compare with $21 \%$ of 1,465 dogs in Indiana, U.S.A. (Ehren- ford, 1956), and a probable similar incidence in the Southern United States of America (Beaver, 1962). Although as yet few studies of the disease in the tropics have been made, there is every reason to believe that it is commoner there than in temperate regions, for, in Calcutta, Maplestone and Bhaduri (1940) found 82 out of 100 dogs to be infected, and in a similar sample in Egypt M. A. Rifaat (personal communication) found an $80 \%$ infection rate.

\section{Discussion}

The wider significance of this work falls into four parts. First, the observed $2.1 \%$ of healthy persons who had a positive skin test underlines the point that toxocariasis, though until recently virtually unknown except to a small number of parasitologists, veterinarians, and ophthalmologists, affects considerable numbers of persons-many more than the few cases in which it has involved and been proved to be present in the eye. In this $2.1 \%$ of infected persons the infection probably has in most instances not produced any serious disease or has resulted in symptoms the cause of which has not been recognized.

Secondly, the finding that $14 \%$ of those who had had poliomyelitis had a positive toxocaral skin test suggests that the two infections are causally related in some cases, the most probable relationship being that the $T$. canis larvae act as vehicles conveying infective agents from the lumen of the alimentary tract to the blood and through it to other tissues, more particularly in this instance the brain and nervous tissue. Recent work which has a bearing on this postulate is that of Wilson and Thompson (1964) and Hutchison (1965). The latter found that faeces from a cat infected with Toxoplasma continued, if the cat was simultaneously infected with $T$. cati, to infect mice for periods long after it could otherwise be expected to do so. This was thought possibly to result from survival of Toxoplasma in the $T$. cat $i$ eggs and transmission of the Toxoplasma to the mice in these eggs. Wilson and Thompson (1964) reported the case of a West Indian woman in whom larvae of Strongyloides stercoralis had acted in a similar way in carrying Escherichia coli from the gut to the blood, and by the blood to the meninges, where it gave rise to fatal meningitis. These studies therefore all bear on one another and strengthen the concept that helminthic larvae can have important effects as vehicles of infection.

The third conclusion to be drawn from this work is that it seems probable that in some cases toxocara larvae reach the brain, and there, on dying, give rise to single or multiple granulomatous lesions, causing epilepsy. Indeed, the work of Brain and Allan (1964) indicates that in some, probably heavily infected, patients epilepsy may develop about seven months after infection, which during the invasive phase may cause encephalitis. In other cases in which epilepsy and evidence of toxocaral infection coexist it is possible that the epilepsy had been associated with soil-eating and consequent ingestion of $T$. canis or $T$. cati ova.

Finally, epilepsy is only one of several diseases to be associated causally or in other ways with toxocariasis, and now categorized in many individual cases as of undetermined or idiopathic origin. It is, for example, known from experimental infection in man (Chaudhuri and Saha, 1959) that the disease in its early stages is associated with eosinophilia, and this, together with the probably large reservoir of infection among dogs in the tropics, renders it probable, indeed almost certain, that some cases of so-called tropical eosinophilia are due to this cause. Important though toxocariasis appears to be in temperate regions, its importance in the tropics is likely to be still greater.

The public-health implications for temperate and tropical regions of the findings here described are clear and need emphasis. 


\section{Summary}

By use of a skin-sensitivity test, evidence of infection with toxocariasis has been found in $7(2.1 \%)$ of 329 apparently healthy persons, in $26(13.6 \%)$ of 191 persons who had had poliomyelitis, and in $26(7.5 \%)$ of 349 sufferers from epilepsy.

It has been confirmed that the reservoir of infection among dogs and cats in the London area is considerable, $21.3 \%$ of dogs and $21 \%$ of cats having been found to have ova of $T$. canis and $T$. cati respectively in their faeces.

It is postulated, and evidence is given to support the view, that larvae of $T$. canis and $T$. cati in their migration from the lumen of the alimentary tract to the blood and tissues, may carry with them bacteria, viruses, and other infective agents, and that in this way some patients have been infected with poliomyelitis.

The larvae do not usually mature in man, but, after wandering in the tissues, die, and a focus of granulomatous tissue reaction forms around their disintegrating bodies. When larvae reach the brain, as they have been shown to do, this process may cause epilepsy. The toxocaral skin test has been found to be positive four times more frequently in epileptic persons than in healthy controls.

It is apparent from this and earlier works that dogs and cats may constitute a considerable public-health hazard.
This study was made possible by a grant from the Medical Research Council, to whom we express our thanks. We are grateful to Lord Brain for helpful suggestions, for his interest in the work, and for suggesting Lingfield as a centre for the investigations on epilepsy, and to Dr. W. W. Gooddy for facilities in the Department of Neurology, University College Hospital. We also thank Sir Herbert Seddon for his help in gaining access to patients who had had poliomyelitis and to the London County Council for some similar facilities. We acknowledge much valuable technical assistance by Mr. A. I. Shah, and are grateful for the grant from the Hospital for Tropical Diseases Research Fund, which made it possible to employ him.

\section{REFERENCES}

Beautyman, W., and Woolf, A. L. (1951). 7. Path. Bact., 63, 635. Beaver, P. C. (1962). Bull. Soc. Path. exot., 55, 555.

Bisseru, B., Woodruff, A. W., and Hutchinson, R. I. (1966). Brit. med. F., $1,1583$.

Brain, Lord, and Allan, B. (1964). Lancet, 1, 1355.

Chaudhuri, R. N., and Saha, T. K. (1959). Ibid., 2, 493.

Chaudhuri, R. N., and Saha, T. K. (1959). Ibid., 2,

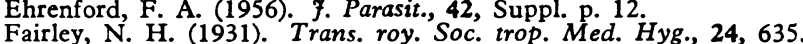

Fairley, N. H. (1931). Trans. roy. Soc. trop. Med. Hy
Hutchison, W. M. (1965). Nature (Lond.), 206, 961.

Maplestone, P. A., and Bhaduri, N. V. (1940). Indian f. med. Res., 28, 595.

Mochizuki, H., Tomimura, T., and Oka, T. (1954). F. infect. Dis., 95, 260.

Ridley, D. S., and Hawgooa, B. C. (1956). F. clin. Path., 9, 74.

Sprent, J. F. A. (1955). Parasitology, 45, 31.

Wilson, S., and Thompson, A. E. (1964). F. Path. Bact., 87, 169.

Woodruff, A. W., and Thacker, C. K. (1964). Brit. med. f., 1, 1001.

\title{
Spontaneous Cerebrospinal-fluid Rhinorrhoea
}

\author{
A. M. NUSSEY,* M.D., F.R.C.P.
}

Brit. med. F., 1966, 1, 1579-1580

Escape of cerebrospinal fluid through the nose is quite common in head injuries, either immediately or after some delay. It may follow nasal or cranial operations, spring from infections of paranasal sinuses or from prolonged pressure on the base of the skull by tumours or hydrocephalus, and sometimes it can be traced to congenital anomalies such as nasal meningocele or meningo-encephalocele.

The diagnosis of spontaneous cerebrospinal-fluid rhinorrhoea is acceptable only when the frequent and less common causes listed above do not apply. Some authors (Coleman and Troland, 1947) would deny the title to cases where an obvious cause, such as a bony defect in the region of the cribriform plate, is found, but such exclusiveness is hardly justified, and even on less rigid criteria the condition is still very much of a collector's piece.

One of the earliest reviews of cerebrospinal-fluid rhinorrhoea was made by St. Clair Thomson in a beautifully written monograph in 1899, but Coleman and Troland (1947), who wrote a classical paper on the subject, were prepared to accept only St. Clair Thomson's personal case and 12 others culled from the literature as fulfilling their criteria of spontaneous cerebrospinalfluid rhinorrhoea. There seems little doubt now that several other cases, such as that of Aubin et al. (1944) in which a minor gap was found in the cribriform plate, which Coleman and Troland rejected, should be included in the series. Coleman and Troland (1947) reported incidentally three further examples, and subsequently reasonably documented single instances have been added by Cloward and Cunningham (1947), Kleinfeld et al. (1950), Kahn (1951), Oldberg (1954), Berryman (1955), Sen Gupta (1956), Troland (1960), Bracewell and Carter (1963), Riser et al. (1964), and three double records by Love and Gay (1947), Rand (1953), and O'Connell (1964) O'Connell (1964) estimated the total number of cases of spontaneous cerebrospinal-fluid rhinorrhoea as less than 75 , and this figure would appear to make a generous allowance for some inaccessible and more doubtful publications.

The ages of the patients have ranged from 25 to 59 , and females have shown a striking preponderance over males in a ratio of about $10: 1$. The feature common to all cases has been the almost constant drip, about as often from one side of the nose as the other, of clear watery material which on analysis could be shown to be cerebrospinal fluid. Position of the head usually influenced the flow, forward flexion particularly making it greater, and, as might be expected, pressure on the jugular veins increased the escape. The quantity of fluid lost has been estimated by a few observers, the average in 24 hours being around 1 pint ( 0.6 litre), but accurate measurement is difficult, especially as the cerebrospinal fluid often drops back into the pharynx and may even find its way into the lungs.

The onset in most cases has been quite abrupt, sometimes after a respiratory infection, but generally for no obvious reason. The condition attracted attention mostly because of the nuisance it gave rise to, but in a few patients single or repeated meningitis, which according to the published accounts (Cloward and Cunningham, 1947 ; Kleinfeld, 1950 ; Troland, 1960) has not been particularly severe, has been an important feature. Besides the drip from the nose some patients have complained, for the reason already mentioned, of a salty taste in the throat, and of an irritating cough.

The duration of the cerebrospinal-fluid rhinorrhoea has varied from weeks to years. The flow ceased at times spontaneously, or after meningitis, or intranasal manipulations such as the instilling of silver nitrate drops, but the therapeutic value of the latter cannot be accepted, because patients treated in this 